\title{
The Making of Top Fine-dining Chinese Restaurants: Evidence from Domestic and International Customers in Australia
}

Dr. Emily $\mathrm{Ma}^{\mathrm{a}^{*}}$ and Dr. Aaron Hsiao ${ }^{\mathrm{b}}$

${ }^{a}$ Department of Hospitality \& Tourism Management, University of Massachusetts, Amherst, US

Email:ema@isenberg.umass.edu

${ }^{b}$ Department of Tourism, Sport and Hotel Management, Griffith University, Brisbane, Australia

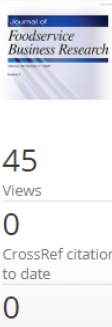

0

Altmetric

$\bar{G}$ Select Language $\mid \mathbf{V}$ ranslator disclaimer
SssRef citations

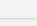

Articles

The making of top fine-dining Chinese restaurants: Evidence from domestic and International customers in Australia

Emily Ma $\boldsymbol{\Xi}$ \& Aaron Hsiao

Pages 113-132 | Published online: 05 Nov 2019

G6 Download citation $\nabla$ https://doi.org/10.1080/15378020.2019.1686899 Chook tor updatos

DFull Article Figures \& data References 6 Citations ABSTRACT

This study examines critical factors for the success of Chinese fine-dining restaurants overseas. Using visualized analysis method of customers' comments, the study found that high-quality food, overall experience (good ambience, attentive staff, appropriate pricing), and good business management are among the top critical success factors, although domestic and international customers perceive restaurant experience differently. The study makes an important contribution to ethnic fine-dining restaurant literature by identifying critical success factors for fine-dining Chinese restaurants overseas and by enriching the concept of food authenticity. 


\begin{abstract}
This study examines critical factors for the success of Chinese fine-dining restaurants overseas. Using visualized analysis method of customers' comments, the study found that high-quality food, overall experience (good ambience, attentive staff, appropriate pricing), and good business management are among the top critical success factors, although domestic and international customers perceive restaurant experience differently. The study makes an important contribution to ethnic fine-dining restaurant literature by identifying critical success factors for fine-dining Chinese restaurants overseas and by enriching the concept of food authenticity.
\end{abstract}

Keywords: Ethnic Fine-dining Restaurants; Sydney; Text Mining; Critical Success Factors 


\section{Introduction}

A recent report from Australian Food News ("Australian's rank Chinese cuisine as their favorite," 2016) shows that Chinese food is Australia's favorite ethnic cuisine. In 2016, $73.6 \%$ of Australians said that they liked Chinese food the most, and Chinese food is popular among all generations in Australia. Over the years, people in the West seem to have developed a taste for ethnic cuisines as alternatives to their traditional cuisines (Josiam \& Monteiro, 2004). Ethnic foods are foods that a particular ethnic or cultural group favors (Clemes, Gan, \& Sriwongrat, 2013). Despite the popularity of Chinese cuisine, Australia and other Western countries have experienced a shortage of high-end Chinese restaurants (Chan, 2017). For example, a quick search on TripAdvisor showed that $60 \%$ of Chinese restaurants in Sydney are categorized as "cheap eats," about one-third are characterized as mid-range restaurants, and only $3 \%$ are categorized as fine dining, suggesting great room for growth in the fine-dining sector.

Fine-dining restaurants provide a unique theme, high-quality expensive food, exceptional service, and a formal ambience (Wilden, Gudergan, \& Lings, 2010; Harden, 2007). Traditionally, fine dining was associated only with French cuisines. However, over time, more ethnic cuisines such as Spanish and Japanese cuisines, joined the fine-dining segment. Presently Japan has the largest number of Michelin three-star restaurants and some Chinese restaurants in Hong Kong and Singapore also appear in the Michelin guide. However, when Chinese food was first introduced in Western countries, it was considered inexpensive ethnic fare (Liu, 2015). As a result, over the years Chinese gastronomy has suffered from a stereotypical image that includes "cheapness" (Wang, 2016), which has little to do with fine dining. This view partially explains the absence of Chinese restaurants in finedining segments and has also negatively affected Chinese cuisines' image and positioning. 
Over the last several decades, immigrants from Asian-Pacific countries have brought various changes to the demographic profiles of Australia. Since 1945, Australia has accepted about 6.5 million immigrants, not only shaping modern Australia as a culturally diverse nation but also influencing Australian cuisines and people's dining habits. Asian cuisines in particular have gained high popularity, and the presence of new migrants from Asian-Pacific countries provides opportunities for Chinese restaurants to step into the fine-dining segment. At present, Australia has only a handful of Chinese fine-dining restaurants, and they have set examples for fellow restaurants.

Parsa et al. $(2005 ; 2015)$ conducted a number of studies on why restaurants fail, providing important theoretical and empirical implications for restaurant researchers and operators. We believe it is also important to investigate critical success factors for restaurants. The purpose of the study is to identify the key ingredients of successful Chinese fine-dining restaurants. Using top-rated Chinese fine-dining restaurants in Australia, the study aims to 1) identify the key factors of successful fine-dining Chinese restaurants in Australia and 2) identify if perceptions differ between domestic and international customers.

The study makes important contributions to both theory and practice. Given the importance of Chinese tourists to the world's travel industry (Smith, 2018) and growing the popularity of Chinese cuisines worldwide (e.g. Australian Food News, 2016; Chen, 2017), we believe such a study is necessary and significant. The findings of the study thus not only enrich literature on fine-dining restaurants, particularly in the ethnic fine-dining restaurant category, but also provide practical operational implications for Chinese restaurants' future strategies. This study also provide evidence on critical success factors of fine-dining restaurants, echoing Parsa et al.'s studies $(2005 ; 2015)$ on why restaurants fail. 


\section{Literature review}

\section{Chinese restaurants and the fine-dining sector in Australia}

Chinese food became part of Australia's culinary tradition during the Australian Gold Rush when, in 1855, 11,493 Chinese migrants arrived in Australia, bringing with them various Chinese cuisines, which quickly became popular throughout the country. By 1890, about onethird of restaurant cooks in Australia were Chinese (Reeves \& Mountford, 2011). Beginning in 1934 , local Chinese-owned businesses (including restaurants) were allowed to bring in employees from China, which further contributed to the growth of Chinese restaurants in Australia (Reeves \& Mountford, 2011). By the 1960s and 1970s, Chinese restaurants were present in every major city and many towns. Although most dishes were altered to accommodate local preferences by adapting ingredients and marrying them with unique Australian ingredients, many typical ingredients of Chinese food, such as tofu, began to appear in Australian kitchens (Metro South Health, 2015).

Today, Chinese gastronomy is an active component of Australia's food culture and is an established part of Australian people's daily life. A recent survey shows that Chinese food is the most popular ethnic fare for Australian people, outperforming Italian, Thai, Indian, Japanese, and other ethnic cuisines (Roy Morgan Research, 2016) (Figure 1).

Despite Chinese restaurants' popularity in Australia, only a handful can be classified as fine-dining restaurants. For example, TripAdvisor (2017) lists only about 3\% of Chinese restaurants as fine-dining. In line with this listing, among the top-10 rated Chinese restaurants in Sydney, three were fine-dining restaurants (TripAdvisor, 2016), suggesting an apparent competitive advantage of fine-dining over other categories of Chinese restaurants. Notably, the three restaurants depart from the conventional image of Chinese restaurants in terms of location, interior design, and atmosphere as well as regarding menus, prices, and authenticity. 
Despite the growing importance of Chinese cuisines and Chinese restaurants, research on this sector by the academic and the industry is limited (Ma et al., 2014). Information is missing with respect to facts such as total number of Chinese restaurants, types of operations, total employment, and contributions to the nation's economy. Further, ambiguity persists as to what makes Chinese fine-dining restaurants successful and how customers perceive their dining experiences.

\section{Customer experience with fine-dining restaurants}

Fine-dining restaurants offer customers upscale foods and beverages provided by celebrity chefs, full table service by highly trained professional servers, and sophisticated and contemporary décor and ambiance (Miller, Tlapa, \& Washington, 2011). In addition, fine dining restaurants create unique concepts to gain a competitive advantage (Ma et al., 2014). As a result of these characteristics, customers visiting dining restaurants often have high expectations, and according to the expectancy-disconfirmation model (Oliver, 1980), can be difficult to satisfy.

Customer satisfaction is critically important for the success of a fine-dining restaurant, because it is the starting point of customer loyalty. Therefore, identifying and assessing the key features of a fine-dining experience is of great significance. Researchers generally agree that the main factors that affect customers' dining experience are the quality of the physical

environment (e.g., W. G. Kim \& Moon, 2009), the menu (e.g., Fotouhinia-Yepes, 2013), food quality (e.g., Ha \& Jang, 2010), and employee service (e.g., Tu, Lin, \& Chang, 2011). In addition, the aesthetic image of fine-dining restaurants is important (Emily Ma, QU, \& Eliwa, 2014).

In restaurants, the servicescape comprises the physical surroundings of the restaurant (Bitner, 1992). Researchers generally agree that the physical environment includes ambient conditions, spatial layout, seating comfort, and facility aesthetics (Hwang \& Ok, 2013). The 
servicescape is important to customers' satisfaction and loyalty because it can inspire emotional responses, such as excitement and pleasure (W. G. Kim \& Moon, 2009; Mehrabian \& Russell, 1974). Physical attributes are particularly important for fine-dining restaurants. For example, the spatial layout of tables can ensure that customers have a comfortable space between them, and artwork, such as paintings, helps to set a mood. Architecture, landscaping, and a view from windows are also important components of a nice servicescape (Elitetraveler, 2017).

The importance of the restaurant's menu cannot be over emphasized. A restaurant should establish a good selection of menu items and design the menu itself well before the restaurant starts operation. The menu is the glue that holds together the restaurant's spatial layout, design, and service style — and, importantly, establishes the customer's perception of the restaurant. The menu's layout and design, sequence of food items, and level of detail can all affect customers' assessment of the restaurant and their expenditure in the restaurant (Schjøll \& Alfnes, 2017). For example, more complex menu descriptions can increase customers' perceptions of the quality of food and liking of the items as well as their price expectation (McCall and Lynn, (2008). Including descriptive labels such as "succulent Asian seafood filet" can improve restaurant sales and evaluations (Wansink, Ittersum, \& Painter, 2004).

While the menu of a fine-dining restaurant does not need to be extensive, the food must be of high quality. Food quality is often determined by the choice of ingredients, the creativity in cooking methods, the presentation of food items, and the taste. Many fine-dining restaurants are proud supporters of local products, using ingredients from local fishermen and farmers. This local patronage not only ensures the freshness of ingredients, it is also a greener option that can contribute to a restaurant's image of being socially and environmentally responsible. 
Successful restaurant operations rely on responsible, hard-working, skilled, and service-oriented employees. Fine-dining restaurant employees need to be skilled at serving customers but also knowledgeable about the menu items so they are able to offer suggestions about food choices as well as food and wine pairing (Mealey, 2015). Fine-dining servers must be attentive to details and willing to go beyond both job requirements and customers' expectations to create memorable experiences for customers (Chang, Kivela, \& Mak, 2011).

An important influence on customers' perception of the restaurant experience is their place of origin and cultural background. An examination of culture's role in customer service experience and satisfaction in a Chinese restaurant found that culture (Asian and American) influenced the relationship between restaurant employees' service and customers' overall satisfaction (Ma, Qu, Njite, \& Chen, 2011). Specifically, when the level of employee service is consistent, Asian customers tend to have a higher level of satisfaction than customers from America. A partial explanation may be that Asian customers are more familiar with Chinese food and are also influenced by the Confucian culture of harmony, and therefore are less likely to express dissatisfaction.

Many customers visiting ethnic-themed restaurants are seeking to experience authentic ethnic cuisines and culture, and a positive correlation exists between customer satisfaction and restaurant authenticity (Tsai \& Lu, 2012). Groves (2001) defined the authenticity of food as a genuine version of a product in relation to a specific place, region, or country, and authentic food can allow an immediately authentic relationship with a culture or tradition (Heldke, 2003). Importantly, as an authentic dining experience is an effective indicator of customer repurchase intention, ethnic restaurants should make efforts to create a more authentic dining experience from the perspective of servicescape, food, and employee service (Ryu, Lee, \& Gon Kim, 2012). Particularly for overseas Chinese customers who have 
had many authentic Chinese food experiences, standards for the authentic taste of food items would be higher than for other attributes.

To summarize, the servicescape, the menu and food quality, authenticity of food, and employee service are critical factors that shape customer experiences with fine-dining restaurants. Creating great customer experience is the very important first step for restaurants' success. Other factors, both internal and external, can also contribute to the success (or failure) of a fine-dining restaurant.

\section{Critical success/failure factors of fine-dining restaurants}

In a milestone study, Parsa et al. (2005) found that about one-third of restaurants fail within the first year of operation. Economic downturns, poor controls, poor locations, failure to adapt to changing demographics, failure to gain market share, restaurant owners' loss of motivation, and failure to cope with technological innovations can all contribute to restaurants' failure (Parsa, van der Rest, Smith, Parsa, \& Bujisic, 2015). However, successful restaurants also share some common characteristics, and efforts have been made to identify and categorize these critical success factors (e.g. Parsa et al., 2015; Jacobs and Klosse, (2016). Table 1 summarizes studies that touch on critical success factors of restaurants. Notably, only a handful of studies were in full-service or fine-dining restaurants contexts (e.g.,Antun \& Gustafson, 2005; Arora \& Singer, 2006; Jin, 2015; Mhlanga \& Tichaawa, 2016), suggesting a research gap that needs to be addressed.

The most important success factors for restaurants is starting with a clear concept. The concept should be distinct enough to stand out in the market (Camillo, Connolly, \& Kim, 2008), and should be supported with good quality food and value created for customers. Restaurant managers should know their specific competitors and view competition strategically, perhaps using competitors' performance to measure self-performance, along the lines of Steve Travel Research's Competitive Set, where hotels compare their own 
performance with a set of identified competing hotels. As creating loyal customers is essential for the success of restaurants (W. G. Kim \& Moon, 2009), a restaurant should make a strong effort at relationship marketing. Researchers and restaurant operators have also emphasized the importance of location, which includes not only accessibility but also the infrastructure, policies, parking and traffic conditions, and neighborhood (Budhwar, 2004).

In addition, capital investment, business models, restaurant size, and the owner's or manager's characteristics are all critical factors that contribute to restaurants' success or failure. Restaurants need managers who can handle fast-paced daily operations and who are equipped with knowledge, capabilities, and appropriate personality traits, such as conscientiousness and self-efficacy (Torres \& Watson, 2013). Managers need to travel and visit units in person and practice effective leadership and human relations (Dipietro et al., (2007). Restaurants should also have effective human resources policies and benefits, as well as policies supporting work-life balance of managers (Lee, Khan, \& Ko, 2008).

\section{Research design}

\section{Using TripAdvisor data}

Online platforms such TripAdvisor, Yelp, Facebook, Expedia, and Priceline provide hundreds of customer reviews on restaurants, hotels, and other hospitality and tourism service providers, which are important references for new customers. The reviews are also important channels for service providers to access customer feedbacks for their service performance. Hospitality and tourism research has commonly used customer online reviews, and TripAdvisor is one of the most popular platforms (Ma, Cheng, \& Hsiao, 2018). TripAdvisor has become the top travel website in the US, with more than 460 million reviews, and in Australia, TripAdvisor has accumulated more than 7,600,000 reviews of hotels, attractions, 
and restaurants (TripAdvisor, 2018). Hence, we have relied on TripAdvisor for online data for our study.

We selected Sydney's Chinese fine-dining restaurants for study as Sydney has the largest number of Chinese immigrants in Australia and is also the top destination city for both domestic and international travelers (Australian Sky, 2018). A search of Sydney restaurants on TripAdvisor using the terms "Chinese" and "fine-dining" returned 14 restaurants. Among them, three had been awarded TripAdvisor's Certificate of Excellence. In addition to being recognized by TripAdvisor, we further verified the fine-dining status of Chinese restaurants by checking if they have won at least one chef hat. The Chef Hat rating system is an Australian equivalent of the Michelin star-rating system which was found in 1977. It is today known as the "Australian Good Food \& Travel Guide". The quality of a 2-Chef-Hat restaurant is considered equivalent to a 2-Michelin-star restaurant.

Using this selection criteria, three restaurants stand out with two been awarded two chef hats and one been awarded one chef hat (Good Food, 2017). Therefore, the three restaurants were retained for the study. To protect the identities of these restaurants, pseudonyms were used (CD, ST, MW). Table 2 included description of each restaurant, including seating capacities, total number of comments generated, and period covered.

\section{Data analysis}

The data were analyzed using Leximancer and SPSS through three stages. First, we conducted text mining of the review comments to identify the key attributes of consumers' fine-dining experience. We then performed a series of analyses of key attributes and reviewers' place of origin. Finally, we undertook some quantifiable measures to assess the influence of reviewers' place of origin and their satisfaction ratings. We performed the first two stages using the qualitative analysis software Leximancer (Edition 4) to identify the key success factors, and to perform the third stage we used SPSS for a cross-tabulation analysis to 
compare customers' place of origin with their satisfaction rating. Leximancer is high-level natural language-processing software that transforms "lexical co-occurrence information from natural language into semantic patterns in an unsupervised manner" through "two stages of extraction - semantic and relational" (Smith \& Humphreys, 2006, p. 262). The outcome of the Leximancer analysis is a heat map, in which the brightness of a circle reflects the importance of a theme and closely mapped concepts have strong semantic meanings (Campbell, Pitt, Parent, \& Berthon, 2011; Rooney, 2005). It has been widely employed in hospitality and tourism literature to analyze review comments (Wu, Wall, \& Pearce, 2014), as well as in academic literature (Cheng, 2016b), blogs (Sun, Zhang, \& Ryan, 2015; Tseng, Wu, Morrison, Zhang, \& Chen, 2015), and newspaper articles (Cheng, 2016a).

\section{Findings}

\section{Ingredients of fine-dining restaurant experience}

Figure 2 shows the conceptual map of the text mining presenting three broad areas: (1) highquality food, (2) overall experience (good ambience, attentive staff, the price factor), and (3) good business management. The analysis yielded 52 concepts, which are grouped into themes under each area. The diversity of themes and concepts in each area reflects the various key attributes of fine-dining restaurants.

Not surprisingly, as Figure 2 shows the most dominant area is high-quality food (Area 1). The themed dishes and menu indicate the variety of food the restaurants offer. Importantly, however, these restaurants offer not only Chinese-specific food but also cocktails and wine, which are usually associated with Western dining restaurants. A fairly extensive wine list is considered important, as well as the way the food is served. For example, customers commented,

Four of us dined here so we were able to try a range of dishes - all were fantasticwaygu beef shin, pork belly, duck and we had three entrees from the dim sum 
menu. The flavours melted in your mouth and the food was crunchy fresh. (CD, Australia, rating 5)

Wine list is fairly extensive - and we all ate really well for only $\$ 100$ per person. Amazing! (ST, Australia, Rating 5)

Customers were also very appreciative that these fine-dining restaurants customized the food upon request.

If you like really well done, spicy, Asian food, this place is it. Actually, it doesn't need to be spicy if you don't like your food that way. That's just what I'd choose. And it is SENSATIONAL! (ST, Australia, Rating 5)

Location also appears as a concept that has a direct connection with the concept of food, reflecting the fact that customers use location to infer the quality of the food. For instance,

The location is cool in a back alley in the basement of an old building. The interior suits the food and creates a great atmosphere, especially sitting near one of the kitchen stations. (MW, Australia, Rating 5)

The restaurant itself is the second dominant area (Area 2), and includes attentive staff, a friendly and busy atmosphere, value for the price, and the restaurant's view of Sydney. In particular, value for money is important: if consumers have chosen a fine-dining restaurant, price might not be a vital consideration, but because these restaurants are fine-dining, consumers look for reasons to justify their spending. For example,

The outstanding service at this excellent restaurant starts at the front door and continues right until you leave. We were greeted, seated and had drinks ordered efficiently with a friendly smile and by then we had seen three wait staff. (MW, Australia, rating 5)

My guest and I paid $\$ 400$ for two people and got the "joy" of watching the wait staff clean around us no doubt so they could knock off early... There are many restaurants in Sydney that do excellent Asian food and have excellent service. This is not one of them. (ST, USA, Rating 1)

The third area is good business management (Area 3), which includes the layout and flow of the restaurant, reservation and waiting-time management, and how staff and managers cope with busy hours and large groups. For example,

We walked in and were greeted by a gorgeous host - with no booking... we chose to sit at the bar ...instead of wait two hours for a table! Perfect outcome! We had the BEST evening. (MW, Australia 5) 
However, when the business management is perceived as ineffective, such as being

unable to cater to the needs of the customers and failing to manage waiting time and customer privacy, the result is customer disappointment and erosion of the customer's perception of value for money. This reaction makes service recovery in a fine-dining restaurant difficult. For instance,

Cannot tell you how disappointed we were. The tables were situated so close that we were privy to all personal conversations. The ambiance was dull, uninviting, bland and requiring a make-over. The food was ordinary, the pork belly was deep fried and tasteless, the duck pancakes were dry and lacked flavor and the Maron sauce I replicate easily out of a bottle. For 1 entree, 2 mains, 1 bottle of wine it cost $\$ 300$. Never again. (CD, Australia, rating 1)

[In] the 1 hour 45 mins there we received our starter, the main never arrived in the 50 min gap after we finished the entree, and another drink we ordered didn't either. The mood was ruined and nothing was going to repair it. The manageress came to me as I left and waived the bill but that's not the point - restaurants please note-TIME, EFFORT AND EXPECTATIONS CANNOT BE REPLACED - WHEN AN EXPERIENCE IS BAD IT'S BAD ON SO MANY LEVELS (ST, Australia, Rating 1)

One important area within the theme is management of privacy. Privacy was frequently mentioned by both international and domestic customers. For example, Excellent food and great service. Not ideal for a formal meal (noise level high and little privacy) but great for an informal business dinner (ST, International, Rating 5).

While Leximancer provides an aerial view of the semantic and relational insights of the textual data, researchers may need to map complex themes and concepts to higher theoretical knowledge (Cheng \& Edwards, 2017). Drawing on the literature, we established a framework linking various attributes to provide an understanding of how customers evaluate a satisfactory experience in fine-dining restaurants. Regardless of its ethnicities, any finedining restaurant needs to have the core attributes of excellent food quality, exceptional service, attentive staff, unique decoration, and a nice view. However, beyond the core attributes, fine dining restaurants also need to have good management skills, be quiet enough to allow private conversation, and serve reasonably sized portions, as when the amount of food is more than they can eat, customers can perceive this as a waste of their money. Finally, 
fine-dining restaurants often offer a "little surprise" for their customers, such as free desert or accommodation of special requests, such as accepting more guests than expected from the booking. Some representative comments are presented below.

We enjoyed a fabulous meal here. I am vegetarian and there was plenty of food to choose from. It was beautifully cooked. The setting is beautiful. I will go again when I go back to Sydney that's for sure. It does come at a price. Our meal was A $\$ 280$ for three of us -we didn't have a sweet but we were given a free one at the end of the night which was rice pudding! (CD, International, Rating 5)

Went here for birthday lunch in April 2017. Friends of ours arrived early, no record of the booking. Our friends thought it was only five of us, not realising there were eight guests. When I arrived, I talked to the staff. Despite the small mistake, can't emphasise enough how helpful and accommodating the team were. Got us a great table outside, were extremely attentive to us, and gave us an after dinner drink to make up for the mix up. Great food, lovely setting, will gladly go back. (CD, Australia, Rating 5)

\section{Customers' place of origin on fine-dining restaurant experience and rating}

To discern whether customers' places of origin would influence their perceived experiences, we relied on likelihood scores. Table 3 presents the likelihood scores of all the concepts of international and domestic consumers. The likelihood score is the indication of conditional probability of a concept in a category (Leximancer, 2011). For example, the likelihood score for the concept banquet ( $72 \%$ ) indicates that $72 \%$ of the text segments with domestic guests also contain banquet. The 20 concepts with top likelihood scores are highlighted in yellow. A zero-order bivariate-correlation analysis on the likelihood scores between international and domestic guests indicates a strong negative correlation $(\mathrm{r}=-.764, p<0.01)$, suggesting that domestic and international customers talked about the key attributes of their restaurant experience differently. While both talked about food, domestic guests tended to talk about the details of the food, whereas international tourists tended to emphasize the overall experience with the restaurants.

This research provides some quantifiable and qualitative measures that assess the influence of reviewers' place of origin on their satisfaction ratings. Using SPSS, we 
performed cross-tabulation analyses between domestic versus international comments. Customer satisfaction ratings are categorized into two categories: average or below (ranging from $1=$ very dissatisfied to $2=$ a bit dissatisfied) and above average (ranging from $3=$ satisfied to $5=$ very satisfied). The results suggested that Australian consumers tended to rate their fine-dining experience more positively than international consumers $\left(\chi_{(1)}^{2}=4.956, p<\right.$ $.05)$. These results may reflect the influence of consumers' previous experience on the evaluation of ethnic restaurants, as international tourists have more chances to experience different kinds of restaurants than domestic customers. Customers' comments support this point. For example:

Went here for a business dinner and we had what they said was a nice set menu. I have lived in Asia for a long time so was hoping for some nice Asian flavours but none of the dishes were a standout. They were all OK...but just not the level of quality or flavour I would expect from a top [restaurant].... (ST, International 3)

Notably,,this research indicates that international customers are more critical and demanding than domestic consumers with regard to the attribute of authenticity. This finding opens a window for future discussions in the area.

\section{Discussion and implications}

This study identified critical ingredients for the success of Chinese fine-dining restaurants, making an important contribution to the restaurant literature. The findings reveal some common elements for restaurants' success, particularly high-quality food and good management.

This research has also demonstrated the current trend and opinions from both domestic and international guests relating to fine-dining Chinese restaurant experiences in Australia. Importantly, domestic guests were more likely to mention the details and quality of food in the reviews. These characteristics are the main reason domestic guests rate the restaurant highly, although the specific details and perception of the quality of food vary with 
the individual. Certain customers refer to excellent taste and the use of fresh ingredients cooked at the right temperature, whereas other customers refer to the chef's special recipes or food plating techniques. International guests were more likely consider the overall experience as important. Generally, customers visit fine-dining restaurants because they seek quality and variety/innovative experience (Harrington, Ottenbacher, and Kendall (2011).

This study also contributes to the debate of authenticity in the restaurant literature. Previous literature on ethnic restaurants consistently suggests that restaurant authenticity crucially influences customer satisfaction and loyalty (Jane, 2012). The results of this study verified that dining environment and authenticity of food play a significant role in prompting more positive reviews from international customers than from domestic guests. International customers are more critical and demanding than domestic consumers in terms of the authenticity of Chinese restaurants. However, a closer examination of the review comments in our research shows that patrons of these restaurants are not limited to nationals of Australia but are a mixture of domestic and international tourists. Thus, experiences of fine dining are formed by the images of past experience and knowledge of customers from various backgrounds with both "insider" and "outsider" perspectives. Customers tend to use various cues to assign authenticity to the food to "validate, educate, miseducate, contradict and interrogate themselves" (Mkono, 2012), such as the use of "Australian Chinese food," supporting the notion that what constitutes an "authentic" Chinese restaurant experience in a fine-dining context is extremely fluid and non-linear.

This study has important managerial implications for restaurants in Sydney and other cities. Local restaurant operators and managers in Sydney, especially those in the fine-dining restaurant segments, can consider the specific findings in this study in tackling their management strategy to improve business performance. More specifically, they can direct particular attention to the creation of a truly superior service climate. Patrons of Sydney's 
upscale restaurants repeatedly mentioned the helpfulness and professionalism of service staff, which is directly linked to how customers perceive the management of the restaurants. More importantly, the management staff in fine-dining restaurants should emphasize professionalism and skills in managing the restaurant in front of the customers, particularly in dealing with crowdedness and unexpected customer requests. As this study shows, customers generally perceived that good management is a reflection of good quality in a fine-dining restaurant.

\section{Conclusion, limitations, and future research}

Using TripAdvisor customer comments on three top fine-dining Chinese restaurants, this study identified key attributes of customers' restaurant experience and uncovered differences between domestic and international customers. The study provided meaningful findings on the segment of ethnic fine-dining restaurants and made important contributions for restaurant operators catering to this market segment.

Despite the significant conclusions arising from the findings, some characteristics of the research settings may limit the generalizability of the study's findings. First, this study used only English-language reviews. Opinions and experiences of international travelers who do not necessarily write fluent English may not have been captured. It seems that international respondents who are able to comment in English are more likely to be experienced travelers. Consequently, they may have different standards for aesthetics and fine-dining Chinese restaurants. Future research might group customer comments on the basis of demographics, such as domestic customers and international travelers and international English-speaking respondents and international non-English-speaking respondents. 
Second, this study relied on reviews of only three fine-dining Chinese restaurants in Sydney. Thus, generalizations of the findings to other forms of ethnic cuisines, such as other Asian or European cuisines, are limited. However, Chinese cuisine has been reported as the most popular ethnic cuisine for Australians (Roy Morgan Research, 2015), suggesting that other cuisines are not as ingrained in Australian culture as Chinese cuisine. Results from study of other cuisines might present different magnitudes and significance for the relationships among the constructs. Thus, future studies should explore the impact of variables such culture and ethnicity on significant performance attributes of authentic finedining restaurants and compare the critical features so as to better tailor them to each ethnic fine-dining restaurant. Additionally, to validate the results of this study, future research could undertake similar studies with diverse ethnic restaurants in other cities to reflect different restaurant segments. 


\section{References}

Agarwal, R., \& Dahm, M. J. (2015). Success Factors in Independent Ethnic Restaurants. Journal of Foodservice Business Research, 18(1), 20-33. doi:10.1080/15378020.2015.995749

Andersson, T. D., Mossberg, L., Restaurang- och hotellhögskolan - Grythytte, a., \& Örebro, u. (2004). The dining experience: do restaurants satisfy customer needs? Food Service Technology, 4(4), 171-177. doi:10.1111/j.1471-5740.2004.00105.x

Antun, J. M., \& Gustafson, C. (2005). Menu success: a menu analysis of awarded fine dining restaurants and private clubs. Journal of Culinary Science \& Technology, 4(4), 1-17.

Arora, R., \& Singer, J. (2006). Customer satisfaction and value as drivers of business success for fine dining restaurants. Services Marketing Quarterly, 28(1), 89-102.

Australian's rank Chinese cuisine as their favorite. (2016). Retrieved from Australian Food News http://www.ausfoodnews.com.au/2016/05/23/australians-rank-chinese-cuisine-as-theirfavourite-roy-morgan-research.html

Bitner, M. J. (1992). Servicescapes: The impact of physical surroundings on customers and employees. The Journal of Marketing, 56 (April), 57-71.

Budhwar, K. (2004). Understanding the success factors for independent restaurants in the Delhi/Gurgaon region: An analysis of the gap between management perceptions and customer expectations. Journal of Services Research, 4(2), 7.

Camillo, A. A., Connolly, D. J., \& Kim, W. G. (2008). Success and failure in Northern California: Critical success factors for independent restaurants. Cornell Hospitality Quarterly, 49(4), 364-380.

Campbell, C., Pitt, L., Parent, M., \& Berthon, P. (2011). Understanding Consumer Conversations around Ads in a Web 2.0 World. Journal of Advertising, 40(1), 87-102.

Chang, R. C. Y., Kivela, J., \& Mak, A. H. N. (2011). Attributes that influence the evaluation of travel dining experience: When East meets West. Tourism Management, 32(2), 307-316. doi:10.1016/j.tourman.2010.02.009

Cheng, M. (2016a). Current sharing economy media discourse in tourism. Annals of Tourism Research, 60 (C), 111-114. doi:10.1016/j.annals.2016.07.001

Cheng, M. (2016b). Sharing economy: A review and agenda for future research. International Journal of Hospitality Management, 57, 60-70. doi:http://dx.doi.org/10.1016/j.ijhm.2016.06.003

Chien, S. Y., \& Lin, Y. T. (2015). The effects of the service environment on perceived waiting time and emotions. Human Factors and Ergonomics in Manufacturing \& Service Industries, 25(3), 319-328.

Czarniecka-Skubina, E., \& Nowak, D. (2014). Japanese cuisine in Poland: attitudes and behaviour among Polish consumers. International Journal of Consumer Studies, 38(1), 62-68. doi:10.1111/ijcs. 12064

DiPietro, R. B., Murphy, K. S., Rivera, M., \& Muller, C. C. (2007). Multi-unit management key success factors in the casual dining restaurant industry: A case study. International Journal of Contemporary Hospitality Management, 19(7), 524-536.

Fotouhinia-Yepes, M. (2013). Menu calorie labelling in a fine dining restaurant: Will it make a difference? Journal of Quality Assurance in Hospitality \& Tourism, 14(3), 281-293.

Gikonyo, L., Berndt, A., \& Wadawi, J. (2015). Critical Success Factors for Franchised Restaurants Entering the Kenyan Market. SAGE Open, 5(4), 1-8. doi:10.1177/2158244015614378

Ha, J., \& Jang, S. S. (2010). Effects of service quality and food quality: The moderating role of atmospherics in an ethnic restaurant segment. International Journal of Hospitality Management, 29(3), 520-529.

Harrington, R. J., Ottenbacher, M. C., \& Kendall, K. (2011). Fine-dining restaurant selection: Direct and moderating effects of customer attributes. Journal of Foodservice Business Research, $14(3), 272-289$.

Heung, V. C. S., \& Gu, T. (2012). Influence of restaurant atmospherics on patron satisfaction and behavioral intentions. International Journal of Hospitality Management, 31(4), 1167-1177. doi:10.1016/j.ijhm.2012.02.004 
Huang, J. (2017). The dining experience of Beijing Roast Duck: A comparative study of the Chinese and English online consumer reviews. International Journal of Hospitality Management, 66 , 117-129. doi:10.1016/j.ijhm.2017.07.003

Hwang, J., \& Ok, C. (2013). The antecedents and consequence of consumer attitudes toward restaurant brands: A comparative study between casual and fine dining restaurants. International Journal of Hospitality Management, 32, 121-131.

Jacobs, G., \& Klosse, P. (2016). Sustainable restaurants: A research agenda. Research in Hospitality Management, 6(1), 33-36.

Jin, N. (2015). Moderating Role of Relationship Quality on the Link between Restaurant Experiences and Customer Loyalty for the Market of Mature Customers. Journal of Quality Assurance in Hospitality \& Tourism, 16(3), 259-282. doi:10.1080/1528008X.2015.1013410

Kim, J., Christodoulidou, N., \& Choo, Y. (2013). Factors influencing customer acceptance of kiosks at quick service restaurants. Journal of Hospitality and Tourism Technology, 4(1), 40-63. doi:10.1108/17579881311302347

Kim, W. G., \& Moon, Y. J. (2009). Customers' cognitive, emotional, and actionable response to the servicescape: A test of the moderating effect of the restaurant type. International Journal of Hospitality Management, 28(1), 144-156.

Lee, H. E. (2015). Does a server's attentiveness matter? Understanding intercultural service encounters in restaurants. International Journal of Hospitality Management, 50, 134-144. doi:10.1016/j.jhm.2015.08.003

Lee, K., Khan, M. A., \& Ko, J.-Y. (2008). Outback Steakhouse in Korea: A Success Story. Cornell Hospitality Quarterly, 49(1), 62-72. doi:10.1177/0010880407307117

Leximancer. (2011). Leximancer Manual Version 4. Retrieved from https://www.leximancer.com/site-media/lm/science/Leximancer_Manual_Version_4_0.pdf

Liu, H. B., Li, H. Y., DiPietro, R. B., \& Levitt, J. A. (2018). The role of authenticity in mainstream ethnic restaurants: Evidence from an independent full-service Italian restaurant. International Journal of Contemporary Hospitality Management, 30(2), 1035-1053. doi:10.1108/IJCHM08-2016-0410

Ma, E., Cheng, M., \& Hsiao, A. (2018). Sentiment analysis-a review and agenda for future research in hospitality contexts. International Journal of Contemporary Hospitality Management, 30(1), 3287-3308.

Ma, E., QU, H., \& Eliwa, R. A. (2014). Customer loyalty with fine dining: The moderating role of gender. Journal of Hospitality Marketing \& Management, 23(5), 513-535.

Ma, J., Qu, H., Njite, D., \& Chen, S. (2011). Western and Asian customers' perception towards Chinese restaurants in the United States. Journal of Quality Assurance in Hospitality \& Tourism, 12(2), 121-139.

Marinkovic, V., Senic, V., \& Mimovic, P. (2015). Factors affecting choice and image of ethnic restaurants in Serbia. British Food Journal, 117(7), 1903-1920. doi:10.1108/BFJ-09-20140313

McCall, M., \& Lynn, A. (2008). The effects of restaurant menu item descriptions on perceptions of quality, price, and purchase intention. Journal of Foodservice Business Research, 11(4), 439445.

Mehrabian, A., \& Russell, J. A. (1974). An approach to environmental psychology: the MIT Press.

Mhlanga, O. (2018). Customer experiences and return patronage in airport hotels: Evidence from OR Tambo International Airport, South Africa. Acta Commercii, 18(1), 1-11.

Mhlanga, O., \& Tichaawa, T. M. (2016). What are the current factors affecting consumer selection criteria in formal full service restaurants in Port Elizabeth, South Africa? African Journal of Hospitality, Tourism and Leisure, 5 (2), 1-11.

Miller, R. K., Tlapa, C. A., \& Washington, K. (2011). Food \& wine festivals. The 2011 Restaurant, Food \& BeveragenMarket Research Handbook: 231-233.

Parsa, H. G., van der Rest, J.-P. I., Smith, S. R., Parsa, R. A., \& Bujisic, M. (2015). Why restaurants fail? Part IV: The relationship between restaurant failures and demographic factors. Cornell Hospitality Quarterly, 56(1), 80-90. 
Ramanathan, R., Di, Y., \& Ramanathan, U. (2016). Moderating roles of customer characteristics on the link between service factors and satisfaction in a buffet restaurant. Benchmarking: An International Journal, 23(2), 469-486. doi:10.1108/BIJ-01-2015-0012

Reeves, K., \& Mountford, B. (2011). Sojourning and Settling: Locating Chinese Australian History. Australian Historical Studies, 42(1), 111-125.

Rooney, D. (2005). Knowledge, Economy, Technology and Society: The Politics of Discourse. Telematics and Informatics, 22(4), 405-422.

Ryu, K., Lee, H. R., \& Gon Kim, W. (2012). The influence of the quality of the physical environment, food, and service on restaurant image, customer perceived value, customer satisfaction, and behavioral intentions. International Journal of Contemporary Hospitality Management, 24(2), 200-223.

Schjøll, A., \& Alfnes, F. (2017). Eliciting consumer preferences for credence attributes in a finedining restaurant. British Food Journal, 119(3), 575-586.

Smith, A. E., \& Humphreys, M. S. (2006). Evaluation of unsupervised semantic mapping of natural language with Leximancer concept mapping. Behavior Research Methods, 38(2), 262-279.

Song, J., \& Qu, H. (2017). The mediating role of consumption emotions. International Journal of Hospitality Management, 66, 66-76.

$\mathrm{Su}, \mathrm{C} .-\mathrm{S}$. (2011). The role of service innovation and customer experience in ethnic restaurants. The Service Industries Journal, 31(3), 425-440. doi:10.1080/02642060902829302

Sukalakamala, P., \& Boyce, J. B. (2007). Customer perceptions for expectations and acceptance of an authentic dining experience in Thai restaurants. Journal of Foodservice, 18(2), 69. doi:10.1111/j.1745-4506.2007.00048.x

Sun, M., Zhang, X., \& Ryan, C. (2015). Perceiving tourist destination landscapes through Chinese eyes: The case of South Island, New Zealand. Tourism Management, 46, 582-595. doi:10.1016/j.tourman.2014.08.010

Thienhirun, S., \& Chung, S. (2017). Influence of List of Values on Customer Needs, Satisfaction, and Return Intention in Ethnic Restaurants. Journal of Hospitality Marketing \& Management, 26(8), 868-888. doi:10.1080/19368623.2017.1331779

Torres, J. L. N., \& Watson, W. (2013). An examination of the relationship between manager selfefficacy and entrepreneurial intentions andperformance in mexican small businesses. Contaduría y Administración, 58(3), 65-87.

Tseng, C., Wu, B., Morrison, A. M., Zhang, J., \& Chen, Y. (2015). Travel blogs on China as a destination image formation agent: A qualitative analysis using Leximancer. Tourism Management, 46, 347-358. doi:10.1016/j.tourman.2014.07.012

Tu, Y. T., Lin, S. Y., \& Chang, Y. Y. (2011). Relationships among service quality, customer satisfaction and customer loyalty in chain restaurant. Information Management and Business Review, 3(5), 270-279.

Wang, H.-Y., \& Wu, S.-Y. (2014). Factors influencing behavioural intention to patronise restaurants using iPad as a menu card. Behaviour and Information Technology, 33(4), 395-409. doi:10.1080/0144929X.2013.810776

Wansink, B., Ittersum, K. v., \& Painter, J. E. (2004). How diet and health labels influence taste and satiation. Journal of Food Science, 69(9), s340-s346.

Wu, M., Wall, G., \& Pearce, P. (2014). Shopping experiences: International tourists in Beijing's Silk Market. Tourism Management, 41, 96-106. doi:10.1016/j.tourman.2013.09.010 


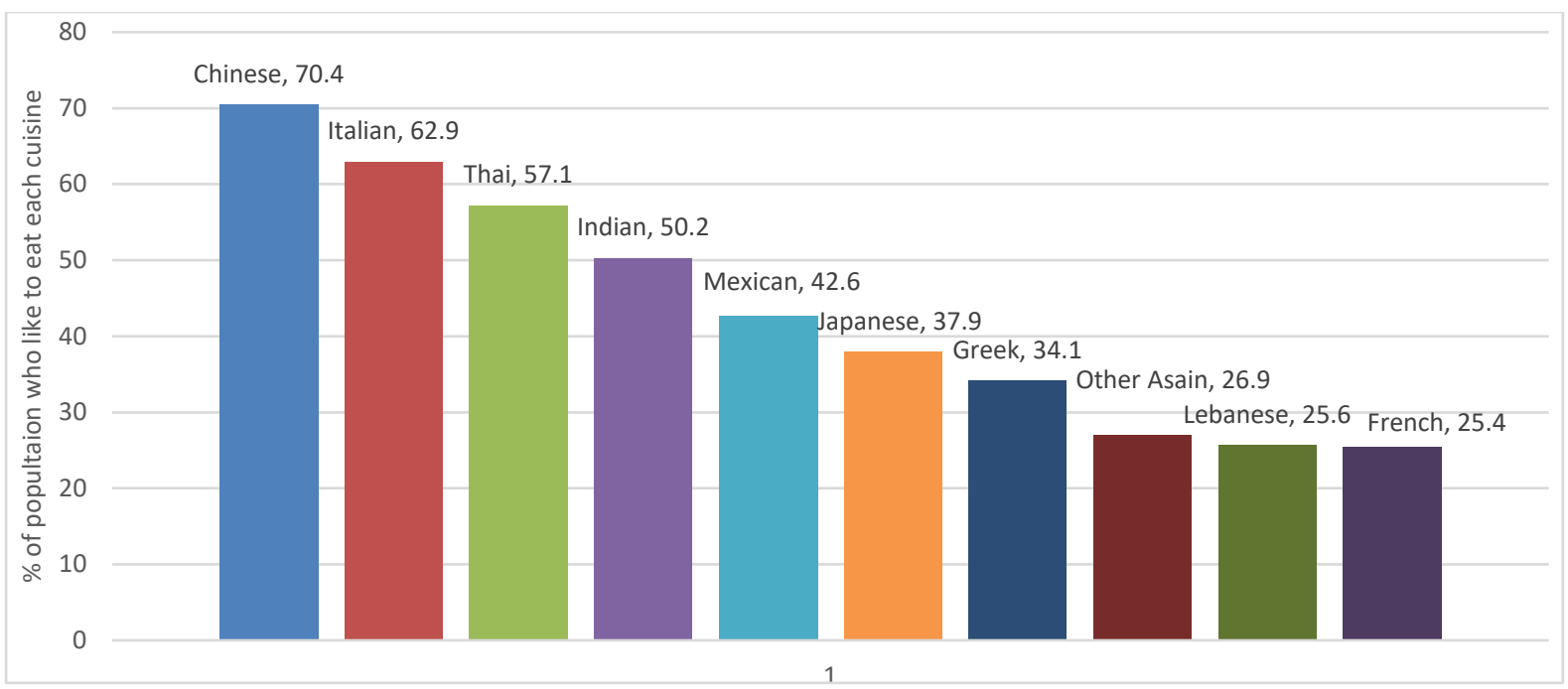

Figure 1. Cuisine liked by Australian customers (adapted from Roy Morgan Research, 2016) 


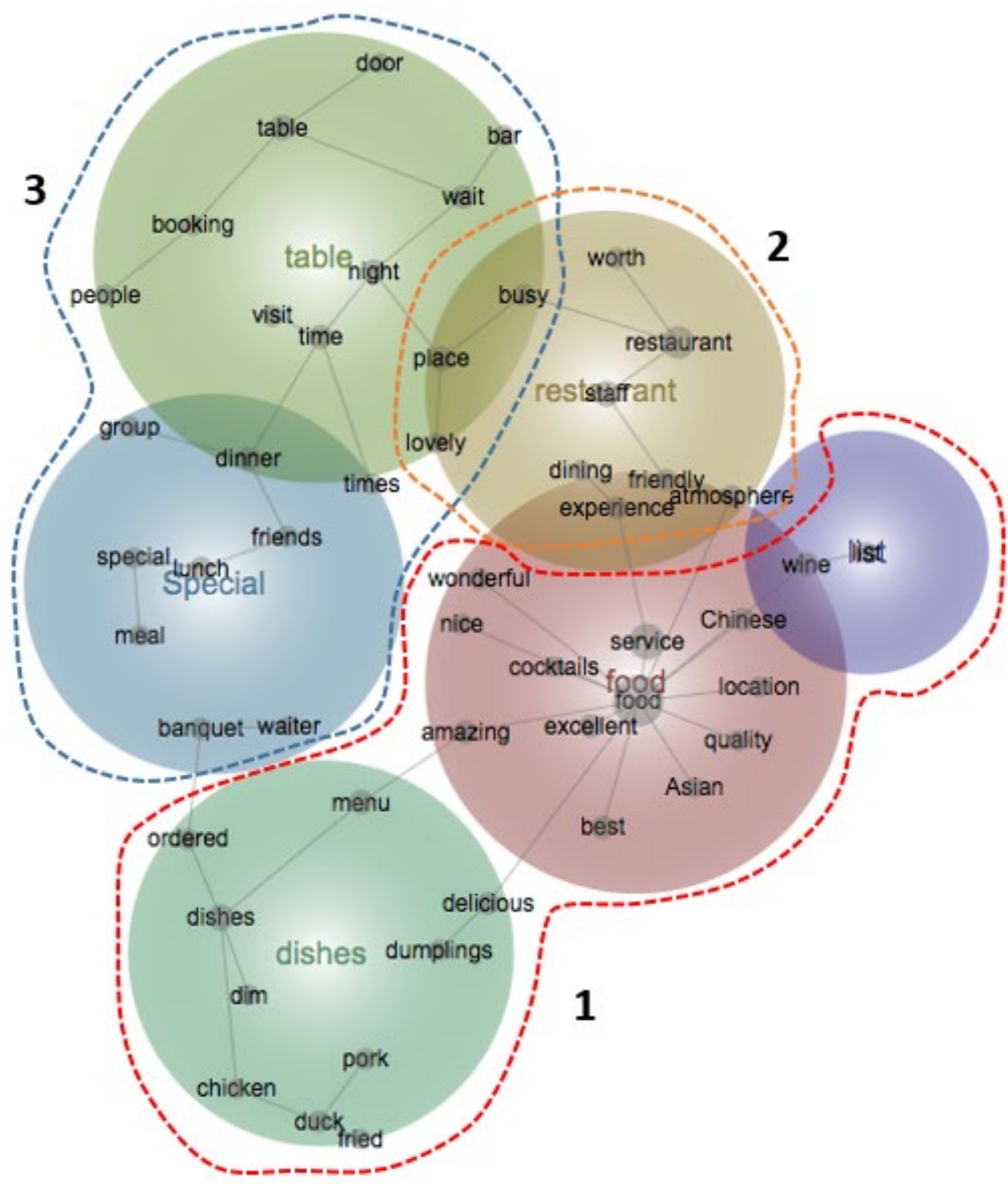

1: High-quality food

2: Overall restaurant experience

3: Good business management

Figure 2. Conceptual map 
Table 1. Critical Success Factors for Restaurants

\begin{tabular}{|c|c|c|c|c|}
\hline $\begin{array}{l}\text { Author } \\
\text { /Year }\end{array}$ & $\begin{array}{l}\text { Cuisine } \\
\text { Ethnicity }\end{array}$ & $\begin{array}{l}\text { Restaurant } \\
\text { Type }\end{array}$ & Critical Success Factors & Research Method \\
\hline (Mhlanga, 2018) & Western & $\begin{array}{l}\text { Airport } \\
\text { context in } \\
\text { Africa }\end{array}$ & $\begin{array}{l}\text { Reliability and empathy were the most important } \\
\text { attributes for customers' restaurant experiences. } \\
\text { Responsiveness and empathy significantly } \\
\text { affected intention to return. Restauranteurs need } \\
\text { to use social and/or economic rewards. }\end{array}$ & $\begin{array}{l}\text { Mixed-methods design. } \\
\text { Interviews with airport } \\
\text { and restauranteur } \\
\text { managers; } \\
\text { questionnaire survey of } \\
602 \text { customers. }\end{array}$ \\
\hline $\begin{array}{l}\text { (Liu, Li, } \\
\text { DiPietro, \& } \\
\text { Levitt, 2018) }\end{array}$ & Italian & $\begin{array}{l}\text { Full-service } \\
\text { restaurant }\end{array}$ & $\begin{array}{l}\text { Make sure the dining environment reflects the } \\
\text { ethnic culture. Pay attention to cuisine name, } \\
\text { presentation, atmosphere, ambience, the } \\
\text { restaurant interior and exterior, as well as } \\
\text { interpretation or storytelling of the ethnic culture } \\
\text { and history of cuisines. }\end{array}$ & $\begin{array}{l}\text { Questionnaire survey of } \\
417 \text { customers of an } \\
\text { independent, full- } \\
\text { service Italian } \\
\text { restaurant in south- } \\
\text { eastern US. }\end{array}$ \\
\hline (Huang, 2017) & Chinese & $\begin{array}{l}\text { Chain- } \\
\text { operated } \\
\text { restaurant in } \\
\text { Beijing }\end{array}$ & $\begin{array}{l}\text { Restauranteurs should provide local cuisine to } \\
\text { both local and foreign customers. Domestic } \\
\text { customers care about value for money while } \\
\text { international visitors are interested in historical } \\
\text { and ritualistic aspects of the culinary arts. }\end{array}$ & $\begin{array}{l}990 \text { randomly selected } \\
\text { online customer } \\
\text { reviews of domestic } \\
\text { and international } \\
\text { visitors. }\end{array}$ \\
\hline $\begin{array}{l}\text { (Thienhirun \& } \\
\text { Chung, 2017) }\end{array}$ & $\begin{array}{l}\text { Japanese and } \\
\text { Thai }\end{array}$ & Casual dining & $\begin{array}{l}\text { Thai customers like Japanese restaurants offering } \\
\text { socialization atmosphere; Japanese customers are } \\
\text { attracted by unique dishes, enjoyment-filled } \\
\text { experience and socialized atmosphere in Thai } \\
\text { restaurants. }\end{array}$ & $\begin{array}{l}\text { On-line and a paper- } \\
\text { based questionnaire } \\
\text { surveys }(\mathrm{N}=345)\end{array}$ \\
\hline $\begin{array}{l}\text { (Song \& Qu, } \\
2017 \text { ) }\end{array}$ & Asian restaurants & Casual dining & $\begin{array}{l}\text { Restaurant should provide products and services } \\
\text { that meet customers' expectations, e.g. develop } \\
\text { varieties of spicy menu items, establish }\end{array}$ & $\begin{array}{l}\text { Questionnaire survey of } \\
449 \text { American frequent } \\
\text { travelers. }\end{array}$ \\
\hline
\end{tabular}


(Mhlanga \&

Tichaawa, 2016)

\section{(Ramanathan, \\ Di, \& \\ Ramanathan,}

2016)

(Jin, 2015)

(Chien \& Lin,

(Gikonyo,

Berndt, \&

Wadawi, 2015)

(Agarwal \&

Dahm, 2015)
Africa

Chinese

\section{Buffet}

restaurant

Formal full-

service

restaurants

Full-service

restaurant

Fast-food

Fast-food restaurant in

Taiwan

Africa

\section{Franchise}

restaurants

Indian, Italian,

Greek, Thai,

Mexican,

French, Chinese, promotion strategies, and focus on functional benefits of new menus.

American customers perceive higher hedonic value when exposed to exotic or cultural atmosphere.

Customer experiences for food, beverage, service and ambience are influenced by social media. Restaurant should promote on social media, particularly on Facebook, Instagram, and YouTube.

Restaurant should allocate resources on the basis of factors' importance to customer satisfaction.

Food is most important, followed by price,

ambience, and service. Male customers value ambience while female and older customers value price.

For senior customers, high level of relationship quality leads to high level of behavioral loyalty. Atmosphere strengthens revisiting intention when customers' satisfaction and trust are low.

Restaurant design influences customers' emotion and purchase. Fast-food restaurant should improve the experience of waiting customers via design and reduce perceived wait. Train staff to respond to waiting customers' emotional needs.

Brand power/concept, competitive environment, government policies, distance management, culture appeal, excellent selection of franchises, good site/location, good relationship with franchisees and proper contract management.

Casual dining College education and prior business experience are important for successful business ventures.

Loyal patrons was ranked third among the success factors of ethnic restaurants.
Questionnaire survey with customers in selected formal fullservice restaurants

Questionnaire survey with 204 restaurant customers.

Web-based

questionnaire of senior diners aged 55 years or older.

Questionnaire survey of leading fast-food chain restaurant in Taiwan

Qualitative study using three interviews with

franchisors operating in the Kenyan market.

Questionnaire survey of 10 ethnic restaurants. 
(Marinkovic,

Senic, \&

Mimovic, 2015)

(H. E. Lee, 2015) Western

(Kawasaki et al., Japanese

(Wang \& Wu,

2014)

(Czarniecka-

Skubina \&

Nowak, 2014)

(J. Kim,

Christodoulidou,

\& Choo, 2013)

Western

Japanese

Western

Western

\section{Casual dining sector}

\section{Quick-service \\ restaurants}

Fine-dining
To promote national cuisine, ethnic restaurants in

Serbia should pay attention to food, prices and

interior design because they are the most

important elements that customers consider when

choosing a particular ethnic restaurant.

Casual dining Servers should develop intercultural intelligence to respond and communicate effectively in service encounters. American customers prefer attentive service as reflected by frequent checkbacks, which influence tips. Japanese customers

have no particular preference on the frequency of check-backs.

Important factors are "utilization of main ingredient flavor" and "cuisine more Japanese in style."

Casual dining MenuPad can improve restaurants' operations, margins, and efficiencies and allow customers to perceive enjoyment and novelty when using MenuPad, which contributes to value creation.

Casual dining For Japanese restauranteurs in Poland, sushi made important contributions to the spreading of Japanese cuisine in Poland. Polish consumers declared interest in Japanese culture and traditions and were inclined to taste the dishes of this region.

Kiosks help to differentiate service, increase

flexibility of operations and increase revenue for quick service restaurants and provide convenience to customers. Restaurants to price, online demos to encourage customers' use of kiosks.
Two studies $(\mathrm{N}=120$; $\mathrm{N}=254$ ) using questionnaire survey of customers.

Questionnaire survey of 975 university students, including American, Japanese students and students of other ethnicities.

Questionnaire survey of 19 chefs

Questionnaire survey (online) with 399 responses

Questionnaire survey of 642 randomly selected Japanese restaurant customers in Poland

Online survey of 614 customers 
(Heung \& Gu,

Japanese,

Chinese fusion,

authentic

Vietnamese,

Western

(Su, 2011)

Japanese, Thai,

Southeast Asian,

Korean, Russian,

Indian, French,

Italian, German,

American

(Camillo et al.,

2008)

Western

Independent

restaurants

\section{(K. Lee, Khan, \& Outback \\ Ko, 2008) Steakhouse in \\ Korea}

(Sukalakamala \& Thai

Boyce, 2007)

Arora \& Singer, American

2006

upscale full-

service

Fast food, buffet and table service

Fine-dining restaurants
Mid- and

restaurants in

Casual dining

Music, equipment, light and color have

significant influences on feelings of customers.

Differentiation strategies; good customer relations; honest, dedicated and determined leadership and restaurant management.

Casual dining Effective human resource practices, e.g. careful employee hiring and generous employee benefits. Best hospitality and value to customers, e.g. serving complimentary chicken wings to waiting customers.

Food being authentic in flavor is more important than the overall atmosphere being authentic.

Emphasize the cultural authenticity via Tha style uniforms, menu using Thai language, traditional Thai greetings, Thai style

tableware/silverware, authentic Thai music and exterior and interior design.
Restaurant's overall performance, particularly on food quality and exceptional service, help improve satisfaction. Ambience influences restaurant choices and values but not satisfaction. Value can be enhanced by improving performance and by reducing prices. Value
Questionnaires survey

of 118 restaurant

customers in HK.

Questionnaire survey of 322 customers

regarding 10 types of

ethnic restaurants.

Mixed-method:

Interview and

questionnaire surveys of 18 restaurants in San

Francisco.

Interviews of

executives and

managers of the

Outback Steakhouse in

Korea

Questionnaire survey of 250 customers.

\section{Questionnaire survey of} 226 fine-dining

restaurants' customers. 
satisfaction and post-visit attitude affect intention to visit the restaurant

\section{(Antun \& \\ Gustafson, 2005)}

NA

Fine-dining

and private

clubs

Menu designs should reflect the demographic components of customers; Emphasize health concerns.

Casual dining

Evening restaurants must provide services

beyond customers' physiological needs.

Restaurants need to provide an environment that

has nice interior design, quality services and

presence of other customers so customers can socialize.

hotellhögskolan -

Grythytte, \&

Örebro, 2004)
Menu analysis of

menus from 36

restaurants

Interviews of 310

customers of 14

restaurants in Sweden. 
Table 2. Profiles of restaurants in the study

\begin{tabular}{llll}
\hline $\begin{array}{l}\text { Fine-dining } \\
\text { Restaurant }\end{array}$ & $\begin{array}{l}\text { Seating } \\
\text { Capacity }\end{array}$ & $\begin{array}{l}\text { Number } \\
\text { of } \\
\text { Reviews }\end{array}$ & Period \\
\hline CD & $\begin{array}{l}\text { Main dining } \\
\text { 60 seats }\end{array}$ & 730 & $2015 / 09 / 25-$ \\
& $\begin{array}{l}\text { Private dining } \\
\text { 40 seats }\end{array}$ & & \\
& Main dining & 1,410 & $2017 / 04 / 09$ \\
ST & 50 seats & & $2017 / 04 / 13-$ \\
& Private dining & & \\
& 12 seats & & \\
& Main dining 240 & 480 & $2013 / 07 / 31-$ \\
MW & seats & & $2017 / 04 / 09$ \\
\hline
\end{tabular}


Table 3. Leximancer likelihood scores of domestic and international consumers

\begin{tabular}{|c|c|c|}
\hline Concept & Domestic & International \\
\hline Banquet & $72 \%$ & $12 \%$ \\
\hline Chicken & $72 \%$ & $16 \%$ \\
\hline Dining & $72 \%$ & $16 \%$ \\
\hline Door & $72 \%$ & $21 \%$ \\
\hline Duck & $72 \%$ & $19 \%$ \\
\hline Dumplings & $72 \%$ & $14 \%$ \\
\hline Friends & $72 \%$ & $14 \%$ \\
\hline Group & $72 \%$ & $19 \%$ \\
\hline Lunch & $72 \%$ & $18 \%$ \\
\hline Menu & $72 \%$ & $21 \%$ \\
\hline Night & $72 \%$ & $16 \%$ \\
\hline People & $72 \%$ & $18 \%$ \\
\hline Quality & $72 \%$ & $18 \%$ \\
\hline Service & $72 \%$ & $18 \%$ \\
\hline Special & $72 \%$ & $16 \%$ \\
\hline Times & $72 \%$ & $17 \%$ \\
\hline Visit & $72 \%$ & $17 \%$ \\
\hline Waiter & $72 \%$ & $23 \%$ \\
\hline Wine & $72 \%$ & $18 \%$ \\
\hline Wonderful & $72 \%$ & $21 \%$ \\
\hline Booking & $63 \%$ & $16 \%$ \\
\hline List & $63 \%$ & $21 \%$ \\
\hline Lovely & $63 \%$ & $20 \%$ \\
\hline Ordered & $63 \%$ & $22 \%$ \\
\hline Atmosphere & $62 \%$ & $19 \%$ \\
\hline Dishes & $62 \%$ & $18 \%$ \\
\hline Fried & $62 \%$ & $20 \%$ \\
\hline Pork & $62 \%$ & $17 \%$ \\
\hline Amazing & $61 \%$ & $18 \%$ \\
\hline Food & $61 \%$ & $23 \%$ \\
\hline Time & $61 \%$ & $20 \%$ \\
\hline Excellent & $60 \%$ & $29 \%$ \\
\hline Experience & $60 \%$ & $18 \%$ \\
\hline Friendly & $60 \%$ & $22 \%$ \\
\hline Nice & $60 \%$ & $26 \%$ \\
\hline Restaurant & $59 \%$ & $26 \%$ \\
\hline Staff & $59 \%$ & $22 \%$ \\
\hline Cocktails & $57 \%$ & $21 \%$ \\
\hline Dinner & $57 \%$ & $27 \%$ \\
\hline Table & $57 \%$ & $28 \%$ \\
\hline Busy & $56 \%$ & $27 \%$ \\
\hline Down & $56 \%$ & $25 \%$ \\
\hline Bar & $55 \%$ & $29 \%$ \\
\hline Delicious & $55 \%$ & $24 \%$ \\
\hline Place & $55 \%$ & $25 \%$ \\
\hline Wait & $55 \%$ & $22 \%$ \\
\hline Location & $54 \%$ & $29 \%$ \\
\hline Meal & $53 \%$ & $24 \%$ \\
\hline Dim & $51 \%$ & $31 \%$ \\
\hline Worth & $50 \%$ & $31 \%$ \\
\hline Best & $49 \%$ & $29 \%$ \\
\hline
\end{tabular}

